\title{
The Relationships Among Changes in GDP, Employment, and Unemployment: This Time, It's Different
}

Juan M. Sanchez, Economist

Constanza Liborio, Research Associate

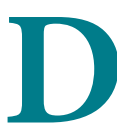

ifferent factors affect gross domestic product

(GDP) and unemployment. However, historically,

a 1 percent decrease in GDP has been associated with a slightly less than 2-percentage-point increase in the unemployment rate. This relationship is usually referred to as Okun's law. ${ }^{1}$ The first chart plots this relationship for 1949-2011 (open circles). The law, however, seems to have changed during the Great Recession.

\section{Recent changes in the relationships among GDP growth, the unemployment rate, and the employment-to-population ratio cast doubt on using these relation- ships to predict future unemployment.}

During the recent recession, the observed decrease in GDP corresponded to a higher increase in the unemployment rate than Okun's law would predict. In 2009:Q4, with only a 0.5 percent decrease in GDP, the unemployment rate rose by 3 percentage points relative to 2008:Q4. According to Okun's law, however, that 0.5 decrease in GDP should have instead corresponded to a 1.5 -percentage-point increase in the unemployment rate. This pattern is reversed in 2011:Q4: A modest increase in GDP was accompanied by a decrease in unemployment significantly larger than what the pre-Great Recession relationship between the data would have predicted. While GDP grew by only less than 2 percent (green circle), the unemployment rate decreased by 1 percentage point. In contrast, Okun's law would have predicted a 0.5 -percentage-point increase in the unemployment rate. The red line in the first chart displays the relationship between 2009:Q4 and 2011:Q4: A 4-percentage-point increase in the unemployment rate corresponds to a roughly 1 percent decrease in output. The most recent trend, thus, is significantly steeper than the one experienced in the past. ${ }^{2}$ This finding is important because it indicates that Okun's law was not useful for predicting changes in the unemployment rate either during the recent recession or recovery.

What explains the significant deviation from the historical experience during these two time periods? One hypothesis is that the two periods are interconnected: During the recent recovery, the unemployment rate decreased more than expected given the actual increase in GDP because during the recent recession the unemployment rate increased more than expected given the actual decrease in GDP. This hypothesis implies that deviations from Okun's law were balanced out between the two periods

\section{Changes in the Unemployment Rate and GDP (1949-2011)}

Unemployment Rate (year-to-year percentage-point change)

5

4

3

2

1

0

0

$-1$

$-2$

$-3$

$-4$

$-5$

$-8$
$-3$

2009:Q4
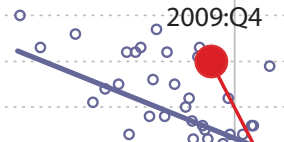

- sod \& 088

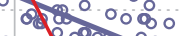

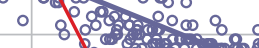

8 80\% 80008 2011:Q4

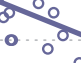

0.0
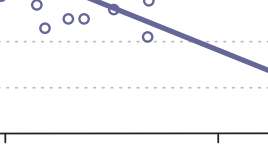

2

17

GDP (year-to-year percent change)

SOURCE: Bureau of Economic Analysis and Bureau of Labor Statistics. 


\section{Changes in the Unemployment Rate and Employment-to-Population Ratio}

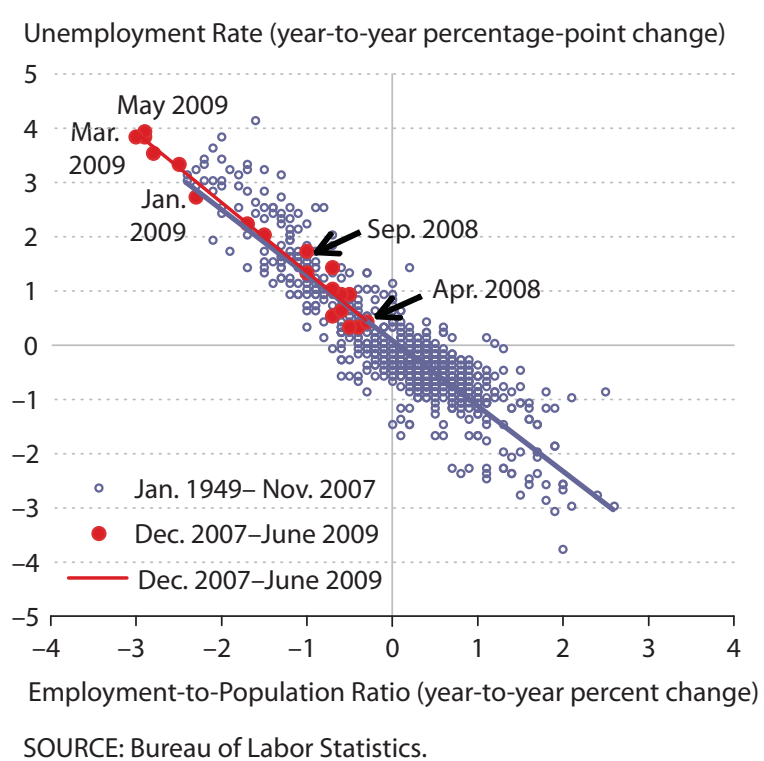

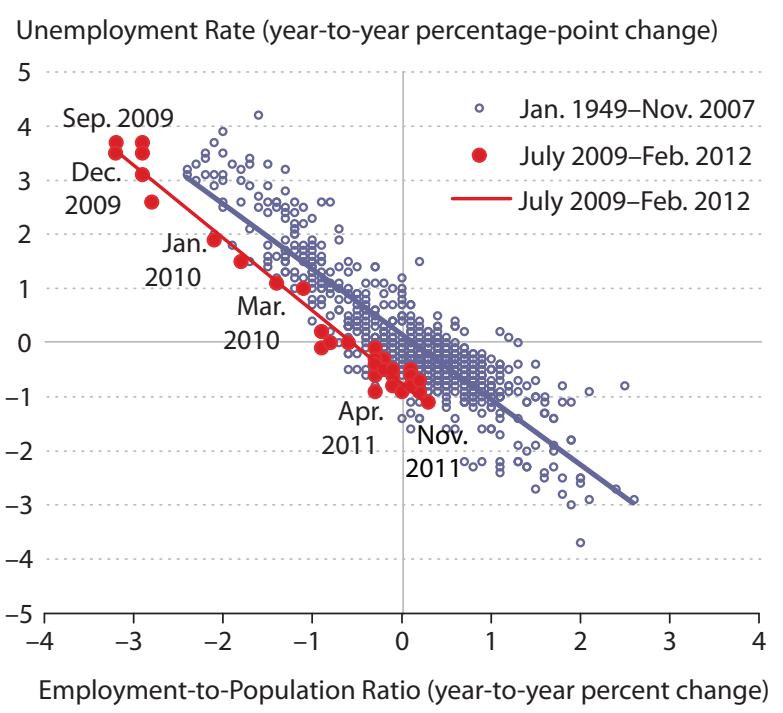

and that the earlier historical data should be usable to perform forecasts going forward.

Our analysis challenges that view. The second chart shows the relationship between the year-to-year percentagepoint changes in the unemployment rate and in the employment-to-population ratio. The open circles in both panels show the historical relationship between these two variables from January 1949 to the peak that occurred one month before the start of the Great Recession. The solid circles show the relationship between the data during the recession (left panel) and since the recovery started in July 2009 (right panel). The blue lines represent the historical relationship, while the red lines represent that relationship estimated for the Great Recession (left panel) and recovery (right panel).

The left panel of the second chart shows that the relationship between the increase in the unemployment rate and the decline in the employment-to-population ratio during the recent recession is in line with the historical pattern. Thus, while changes in GDP were not useful for predicting changes in unemployment during the recent recession, changes in the employment-to-population ratio were-unemployment during the Great Recession increased significantly because the ratio decreased proportionally.

The right panel of the second chart shows a different story for the recovery, however. In particular, during the recovery the relationship between changes in the unem- ployment rate and the employment-to-population ratio shifted away from the historical pattern. The same increase in the ratio experienced during the recent recession now corresponds to a larger drop in the unemployment rate. The historical relationship implies that if the employmentto-population ratio is constant, the unemployment rate will be roughly constant. The relationship estimated for the recovery implies that the unemployment rate drops by 1 percentage point even when the ratio remains constant. Thus, compared with the historical experience, changes in the employment-to-population ratio alone do not explain the significant decline in the unemployment rate during the recent recovery.

Our analysis suggests that in recent years there have been changes in the relationship between (i) GDP growth and changes in the unemployment rate and (ii) changes in the employment-to-population ratio and changes in the unemployment rate. These changes cast doubt on using these relationships to predict future unemployment.

\footnotetext{
${ }^{1}$ The law is named after economist Arthur Melvin Okun, who first measured the relationship between the two variables in the early 1960s. See Okun, Arthur M. "Potential GNP: Its Measurement and Significance," in Proceedings of the Business and Economic Statistics Section of the American Statistical Association. Alexandria, VA: American Statistical Association, 1962, pp. 89-104.

${ }^{2}$ For more details on calculations of Okun's coefficient, see Knotek, Edward S. II. "How Useful Is Okun's Law?" Federal Reserve Bank of Kansas City Economic Review, Fourth Quarter 2007, 92(4) pp. 73-103.
} 